\title{
Improvement of Weight and Body Composition in a Group of Women through a Weight Management Program Using Food Supplements with or without a Hypocaloric Diet
}

\author{
Magdalena Rafecas ${ }^{1}$, Laura-Isabel Arranz ${ }^{1, *}$, Mireia García ${ }^{\#}$, Miguel-Ángel Canela ${ }^{\dagger}$ and \\ DIECA Group $\$$
}

${ }^{1}$ Department of Nutrition and Food Science (University of Barcelona), Faculty of Pharmacy, Avda. Joan XXIII, $s / n$., Barcelona 08028, Spain

\begin{abstract}
Overweight is an increasing health problem characterised as a higher than normal body weight due to an abnormal increase in body fat. Body weight adequacy is categorized by using body mass index (BMI), however other parameters such as fat mass (FM), waist circumference (Wci) or waist to hip ratio, are relevant. Ideally, body composition should be calculated initially to evaluate changes during a dietary intervention of weight loss. Hunger experience is another parameter to take into account. The aim of this study was to assess the improvement of weight and body composition through the use of food supplements to control hunger, with and without a hypocaloric diet prescription. 252 women who wanted to lose weight were recruited in the program and splitted into two groups and were monitored for 8 weeks. Anthropometric measures (weight, height, body mass index, fat mass, waist and hip circumference) were taken. The mean age was of $36.84 \pm 7.29$ and most of them were within overweight or obesity values for BMI, FM, Wci and hip circumference. After 8 weeks, both groups got significant results, achieving not only weight loss but also reduction in body mass index, fat mass, and waist and hip circumferences. However, as expected, improvements were better in FS+diet than in FS group. There is a need to tackle overweight and obesity individually, taking into account the personal characteristics of the patient. Food supplements may be useful to manage hunger and professional individualised assessment is critical to succeed.
\end{abstract}

Keywords: Overweight, body mass index, anthropometric measures, food supplements, hunger, hypocaloric diet.

\section{INTRODUCTION}

Overweight and obesity are increasing health problems worldwide, related to an increased risk of diseases like type 2 diabetes, dyslipemia, hypertension, coronary heart disease, some type of cancers, osteoarthritis, and others [1]. In Spain, the prevalence of obesity in adults is around $17 \%$ and obesity plus overweight is around $54 \%[2,3]$. Both are characterized as a higher than normal body weight due to an abnormal increase in body fat storage. Body weight adequacy is categorised using body mass index (BMI), however other parameters as fat mass (FM), waist circumference (Wci) or waist to hip ratio, are relevant and useful. BMI is calculated as the body weight $(\mathrm{kg})$ divided by the height square $(\mathrm{m} 2)$ and the established categories are shown on Table 1. Waist circumference is the distance around the abdomen and

\footnotetext{
*Address correspondence to this author at the Department of Nutrition and Food Science (University of Barcelona), Faculty of Pharmacy, Avda. Joan XXIII, s/n., Barcelona 08028, Spain; Tel: 934024527 - 934024 508; Fax: 934 035 931; E-mail: lauraarranz@ub.edu

\#Dietitian nutritionist of DIECA group (DIECA is the acronym in Spanish of Diet, Exercise, Food supplements)

${ }^{\dagger}$ Department of Managerial Decision Sciences, IESE Business School. Barcelona.

\$DIECA Group of dietitians: Sarola J, Díaz MS, Pérez E, Martínez L, Maximiano C, Esteba E, Roura C, Viñolas I, Romero I, Caseiro J, Cerón T, Vilanova P, Sales LI, Gutiérrez A, del Río MC, González A, Nolasco V, Hernández AB, Cuberos C, Aguilar MP, Almagro L, Gandía M, Sanz Y, López P, Uriol T, López M, Sánchez C, Esquer P, de la Fuente V, Viñas G, López V, Domínguez $\mathrm{N}$.
}

this measure is used to assess the degree of abdominal obesity and also cardiovascular risk. Hip circumference $(\mathrm{Hci})$ is recorded on the widest part of the hips. It is considered that for a good health, waist should measure no more than $80 \mathrm{~cm}$ in women and $94 \mathrm{~cm}$ in men, and abdominal obesity exists when waist circumference is more than $88 \mathrm{~cm}$ in women and $102 \mathrm{~cm}$ in men [4], or when the waist to hip ratio is above 0.85 in women and 0.9 in men [5]. Ideally, body weight and body composition, with all these anthropometric parameters, should be calculated initially in order to evaluate changes during a dietary weight loss intervention [6].

Table 1: International Classification of Adult Underweight, Overweight and Obesity According to BMI. Source: Adapted from WHO, 1995, WHO, 2000 and WHO 2004

\begin{tabular}{|c|c|}
\hline Classification & BMI $\left(\mathbf{K g} / \mathbf{m}^{2}\right)$ \\
\hline \hline Underweight & $<18.50$ \\
\hline Normal range & $18.50-24.99$ \\
\hline Overweight & $25.00-29.99$ \\
\hline Obese class I & $30.00-34.99$ \\
\hline Obese class II & $35.00-39.99$ \\
\hline Obese class III & $\geq 40.00$ \\
\hline
\end{tabular}


Another issue to take into account is the fact that changing behaviours and habits related to health are not easy. It is hard to quit smoking, to start in physical activity, and specially to change eating patterns. All are difficult challenges for anyone in spite of having a health benefit as a result [7]. It is also considered that people without basic nutrition knowledge would have worst criteria to choose what they eat. However, nutrition knowledge is not the unique factor to achieve changes in consumers' food behaviours [8]. Moreover, epidemiologic studies have begun to show links between adiposity and behaviours such as television watching, alcohol intake, stress, and sleep deprivation because they are likely to contribute to overweight and obesity by encouraging excessive eating [9, 10]. Regarding exercise, there are physiological, psychological and behavioural factors potentially involved in its relationship with appetite. People who exercise, frequently compensate for the increase in energy expenditure via compensatory increases in hunger and food intake. However, this is not always likely to happen, and responses to exercise will vary. Understanding and characterising this variability will help weight loss strategies to suit individual needs [11]. Consequently, consciousness, knowledge, attitude and lifestyle must be addressed by health professionals when giving advice.

Obviously, what we eat is tremendously important to weight control. Hypocaloric diets are one of the main weight loss tools which, along with exercise, facilitate the achievement of a negative energetic balance (to eat fewer calories than wasted). However, there is a factor that determines whether a hypocaloric diet would be successful or not, it is hunger experience. Satiation is the process that causes one to stop eating and satiety is the feeling of fullness that persists after eating, suppressing further consumption. Both are important in determining total energy intake. Therefore, to achieve and maintain a good satiety level is essential and a relevant issue to take into account in order to help people to follow their diets $[12,13]$. Although there is a lot of individual variability, generally, it is feasible to distinguish two hunger profiles. On the one hand people who eat big amounts of food in each main meal (satiating behaviour), and on the other hand people who eat many times during the day (snacking behaviour). Both behaviour, although are different, lead to an extra food intake during the day, and therefore to eat more calories than needed.

Some dietary products are formulated specifically to improve satiety sensation and would be of help in hunger management. These products are marketed as food supplements (FS) and among their ingredients some of the most popular are Konjac mannan (glucomannan), oat fibre, saffron extract and chromium. All of them have demonstrated some actions related to satiety mechanisms. The one with the greater evidence seems to be Konjac mannan which holds studies demonstrating its efficacy for weight loss when used along with hypocaloric diets [14, $15,16,17]$. Oat fibre has a similar action than glucomannan and other soluble fibres as fructooligosaccharides [18], increasing satiety after meals by slowing down carbohydrate absorption. However, some of the benefits of oat fibre are due to beta-glucans [19, $20,21]$. Chromium is widely used in food supplements addressed to weight control. It has the function to contribute to insuline action, maintaining plasma glucose levels [22], and therefore presumably with a beneficial effect improving satiety $[23,24,25,26]$. There is a newer ingredient within the field of weight and satiety, saffron, specifically, the Crocus sativus $L$. extract, which has shown to reduce snacking behaviour and increase satiety [27]. Crocus sativus L. has also effects on anxiety and depression which seemingly would be related to snacking behaviour [28, 29, 30, 31]. Food supplements based on these ingredients could be of help for people who want to lose weight and to manage hunger in order to follow hypocaloric diets much better. Moreover, people seek these products looking for an easier solution to their weight problems, not always completely conscious that they could be of help although a change in dietary habits and life-style is also needed.

All these data show that weight loss is a difficult challenge due to the big variability among people and all affecting factors. All of them must be taken into account to individually advice the best way for a successful weight management outcome.

\section{OBJECTIVE}

To assess the improvement of weight and body composition through the use of food supplements to control hunger with and without hypocaloric diet prescription.

\section{METHODS}

In order to recruit participants, we organized an open and free weight loss program for people with excess body weight who wanted to slim some kilograms. The inclusion criteria established for the study were: healthy women between 20 and 45 years 
old, with overweight (based on self-perception). We excluded from the participation men, and people with chronic diseases or who were under chronic medical treatments. A first call, offering free participation and explaining conditions to be on, was made by Internet, and a second call was made to people attending dietitian offices located in different areas of Spain. The call lasted for some days.

Selected participants were asked to answer a questionnaire about their age, their weight and height, their life history with slimming diets, weight they wanted to lose and hunger experience. We also took measures of weight, body mass index, fat mass percentage and waist and hip circumference. Weight, BMI, and FM percentage were taken with an OMRON BF511 body composition analyser. Waist and hip circumference were taken with a common tape and measured in centimetres $(\mathrm{cm})$. The waist measure was made with person with a normal breath, starting at the top of the hip bone, bringing a tape measure all the way around, and levelling with the belly button, making sure it was not too tight and that it was straight. Similarly, hip was measured at its widest portion of the buttocks. Participants were assigned to two intervention groups. Those selected from the internet call followed general recommendations of hypocaloric Mediterranean diet (FS group), and those selected from dietitians offices received individualised hypocaloric diet (FS+diet group).

During 8 weeks all participants within both groups consumed one specific food supplement addressed to tackle hunger and improving satiety. Food supplements used were two different ones, both addressed to manage hunger, one formulated to people with satiating behaviour and the other one to snacking behaviour. Within each group, participants with satiating behaviour were recommended to take the specific food supplement containing glucomannan, chromium and oat fibre, and people with snacking behaviour were recommended to take the specific food supplement containing saffron extract, chromium and fructooligosaccharides. These food supplements were Lipograsil ${ }^{\circledR}$ Saciante and Lipograsil ${ }^{\circledR}$ Control entre Horas respectively and were provided by Zambon, S.A.U.

All participants were visited three times (first day, at week 4 and at week 8), and anthropometric measurements (weight, BMI, percentage of body fat, waist and hip circumference) were taken in each visit. All dietitians visiting them were instructed to standardise inclusion criteria and methodology. For each anthropometric parameter, we tested the mean difference between the FS and the FS+Diet group using a 2-sample $t$ test and the individual changes during the study using a paired t test.

\section{RESULTS}

Nearly 2000 women responded to the call launched over the Internet, and almost 40 dietitians agreed to collaborate in the study. From the call via Internet 128 women were selected and included in FS group, and each dietitian included a mean of 5 participants, with a total of 124 included women who were the FS+diet group. Finally, 252 women agreed and attended to our first visit and were enrolled in a weight loss program for 8 weeks.

The mean age within the whole group of participants was of $36.84 \pm 7.29$ years, within FS group was of $36.4 \pm 6.45$ and within FS+diet group was of $37.5 \pm 8.41$. As the median value for the whole group was 37 years, most of our participants were in perimenopause period, and most of them referred body changes typical of this period.

About eating behaviour, 123 women showed a hunger experience profile, i.e. excessive appetite at main meals, and 129 showed a snacking profile, eating more frequently between main meals (see more details in Table 2). The lack of satiety was expressed spontaneously as the main difficulty to control or lose weight. Weight they wanted to lose was of $11.8 \pm 5.68$ $\mathrm{kg}$ in the FS group and $11.16 \pm 6.35 \mathrm{~kg}$ in the FS+diet group, with differences among participants from 3 to 20 kilograms.

The mean value of initial BMI was 28.6, corresponding to a grade II overweight range. However, 27 were in normal BMl values, 145 within overweight BMI range (only 2 of them within overweight grade I range), and 78 showed BMI values within obesity range. The mean value for body FM percentage was of 37.92 lying within the category of obesity, according to reference criteria [6]. In fact, most of participants had, at the beginning of the program, a FM percentage higher to the considered as normal or healthy, even those who had normal BMI values. Only 7 participants had an initial FM percentage equal to or below 27, which would be the desirable value for women at this age.

Among all the participants, Wci and Hci values were generally high, with a mean value of 90.32 and 109.36 
Table 2: Anthropometric Values and other Characteristics within FS and FS+diet Group. Mean Age (Years), Mean Wanted to Lose Weight, Participants with a Satiating Behaviour, Participants with a Snacking Behaviour, Body Mass Index (BMI), Percentage of Fat Mass (\%FM), Waist Circumference (Wci), hip Circumference (Hci)

\begin{tabular}{|c|c|c|c|}
\hline & FS (n=128) & FS+diet $(\mathbf{n = 1 2 4 )}$ & p value \\
\hline \hline Mean age (years) & $36.4 \pm 6.45$ & $37.5 \pm 8.41$ & - \\
\hline Mean wanted to lose weight $(\mathrm{kg})$ & $11.8 \pm 5.68$ & $11.16 \pm 6.35$ & - \\
\hline Satiating behaviour & 61 & 62 & - \\
\hline Snacking behaviour & 67 & 28.69 & 0.957 \\
\hline BMl & 28.66 & 39.05 & 0.006 \\
\hline \%FM & 36.79 & 92.65 & 0.001 \\
\hline Wci & 88 & 109 & 0.539 \\
\hline
\end{tabular}

Table 3: Description of Waist Circumference (Wci). Number of Participants within Normal, Overweight and Obesity Wci Values, and Mean Wci Value within each Group

\begin{tabular}{|c|c|c|c|}
\hline & Wci $<\mathbf{8 0} \mathbf{c m}$ (normal) & Wci 80-88cm (overweight) & Wci >88cm (obesity) \\
\hline \hline Number of participants (total $\mathrm{n}=238)$ & 29 & 77 & 132 \\
\hline Mean Wci (cm) & 75 & 84 & 97.1 \\
\hline
\end{tabular}

respectively. For Wci most of our participants were at obesity values (see Table 3 ). Moreover, $32.8 \%$ of the participating women had a waist to hip ratio higher 0.85 , indicating that almost one third of them had abdominal obesity.

Anthropometric measures within FS and FS+diet group were in general very similar, for BMl values difference were not statistically significative $(p=0.957)$ and for FM percentage difference was statistically significative $(p=0.006)$. Hci values were almost equal for FS and FS+diet groups, however Wci values were also significantly different $(\mathrm{p}=0.001)$ (see Table 2 ).

In general, there was a decrease on measured parameters (weight, BMI, FM, Wci and $\mathrm{Hci}$ ), although these results were greater within the FS+diet group, due to the synergic effect of the food supplement along with hypocaloric diet.

Among the FS group $(n=128)$ the mean weight loss after 8 weeks was of $2.206 \mathrm{~kg}$, BMI diminished 0.798 points and FM percentage decreased a mean of 2.314 points. Within this group, women who followed properly the given recommendations about the use of the FS and also about hypocaloric Mediterranean diet $(n=38)$, had better results, with a mean decrease in weight, $\mathrm{BMI}$ and FM percentage of $2.82 \mathrm{~kg}, 1.01$ y 3.95 respectively. Regarding $\mathrm{Wci}$ and $\mathrm{Hci}$ it was also observed also a mean decrease of $1.686 \mathrm{~cm}$ and 1.771 $\mathrm{cm}$ respectively and a better outcome within women with a good performance of the given instructions with reductions of $2 \mathrm{~cm}$ for Wci and 2.26 for Hci (see Figure 1).

Among the FS+diet Group $(n=124)$ the mean weight loss after 8 weeks was of $3.72 \mathrm{~kg}$, BMl diminished 1.476 points and FM percentage decreased a mean of 2.65 points. Women within this group following properly the given recommendations, in this case about the use of the FS and also about hypocaloric prescribed diet $(n=56)$, had better results, with a mean decrease in weight, BMI and FM percentage of $4.61 \mathrm{~kg}, 1.76$ y 3.06 respectively. Wci had decreased a mean of $4.55 \mathrm{~cm}$ and Hci $4.98 \mathrm{~cm}$. Also a better outcome was achieved within women who performed well, with reductions of $5.03 \mathrm{~cm}$ for Wci and 4.98 for Hci (see Figure 2).

Both groups got good results, however, as expected, improvements were better in the FS+diet than in the FS group. All the outcomes were statistically significant $(p<0.05)$ and are complied in Table 4 and Figure 3 (for weight, fat mass and waist circumference).

Another interesting aspect of this study was to observe the adherence to the dietary recommendations. Women who participated in FS+diet group followed diet advice and took recommended food supplements more regularly than those women 


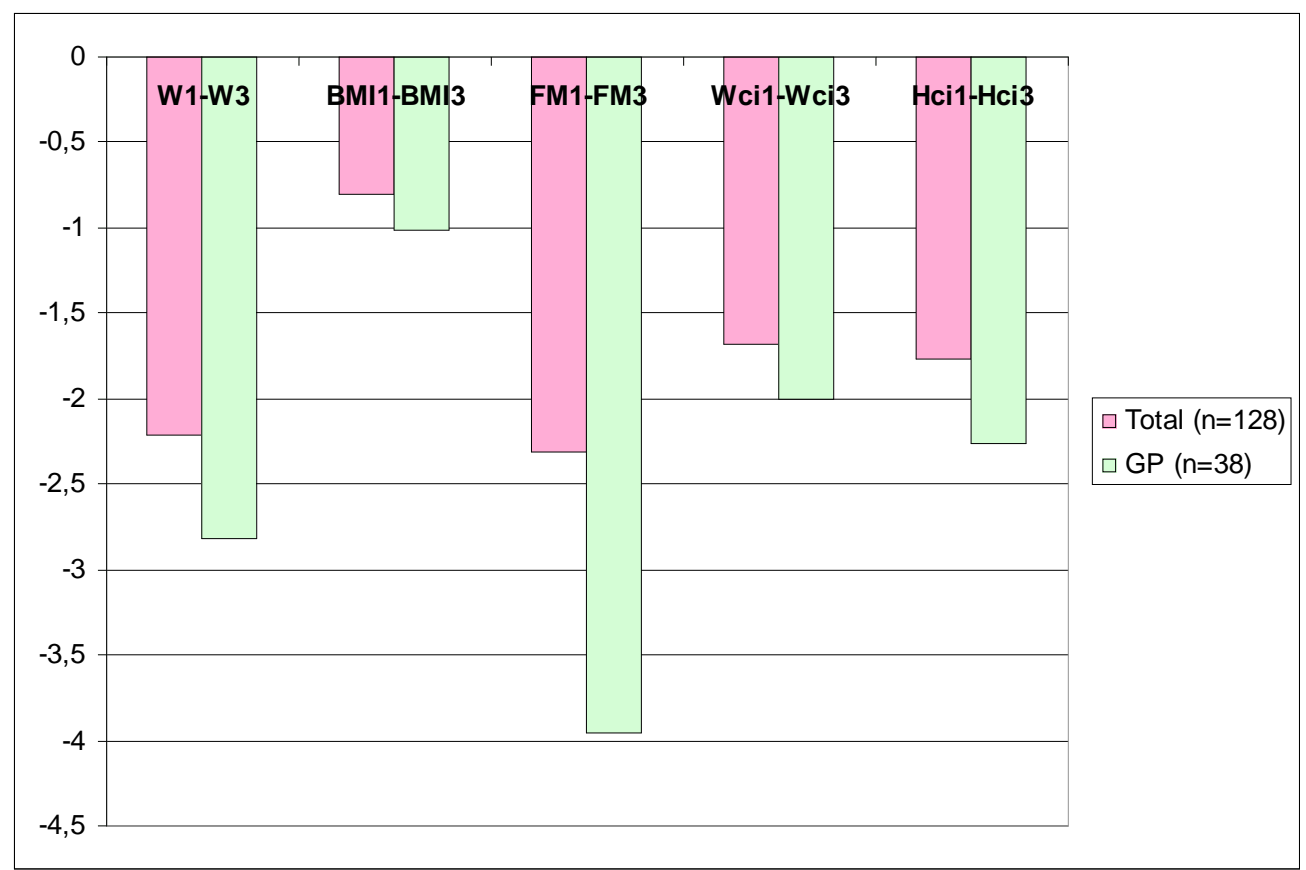

Figure 1: FS group results. Differences between measurements at week 8 and first day of weight (W1-W3), body mass index (BMI1-BMI3), fat mass percentage (FM1-FM3), waist circumference (Wci1-Wci3) and hip circumference (Hci1-Hci3), within the whole group $(\mathrm{n}=128)$ and women with a good performance (GP).

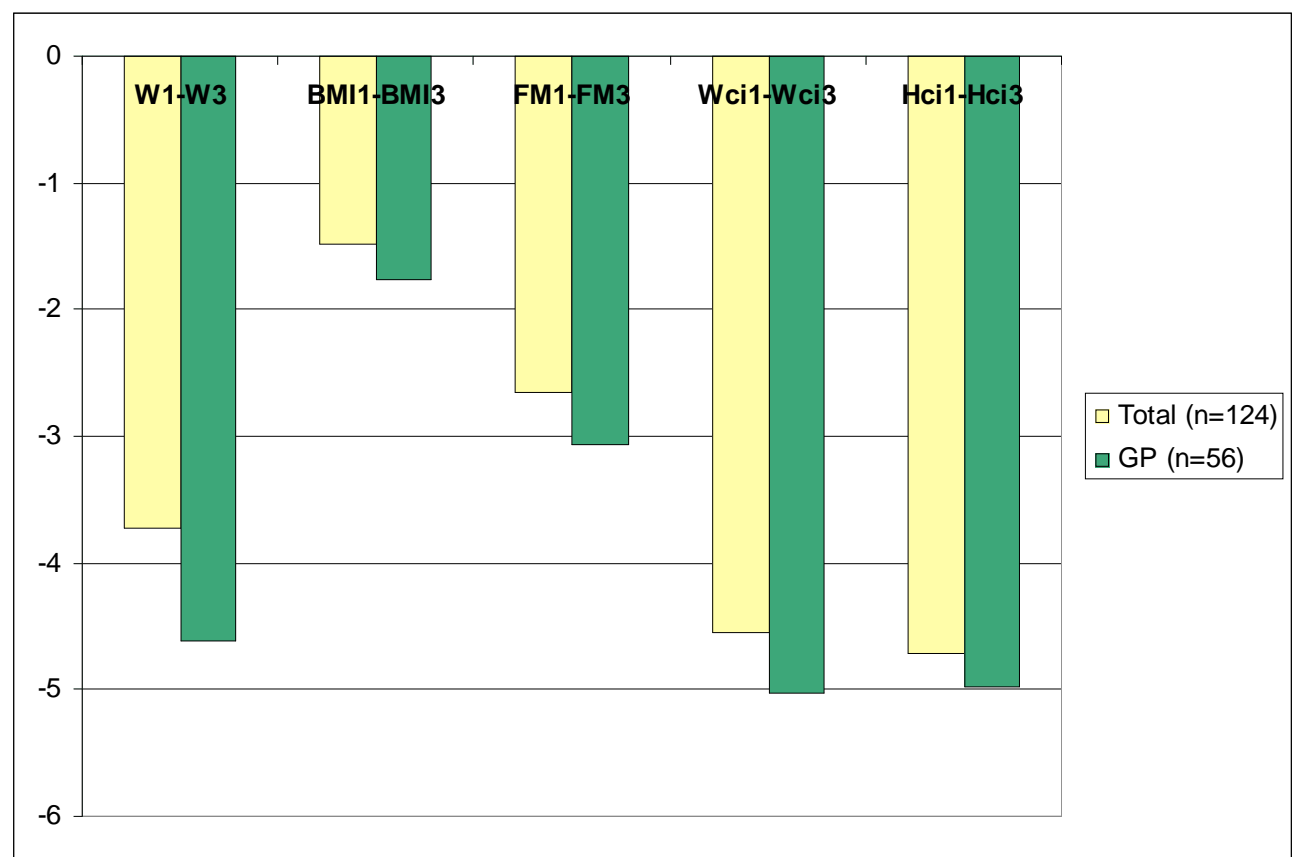

Figure 2: FS+diet group results. Differences between measurements at week 8 and first day of weight (W1-W3), body mass index (BMI1-BMI3), fat mass percentage (FM1-FM3), waist circumference (Wci1-Wci3) and hip circumference (Hci1-Hci3), within the whole group ( $n=124)$ and women with a good performance (GP).

participating in FS group. Within the FS group 51 of 128 participants finished the 8 weeks program, and within the FS+diet group, 95 of 124 participants completed it. FS+diet women had a better adherence ratio to the program probably due to greater initial motivation and personal attention by the dietitian.

\section{CONCLUSION}

Overweight and weight management are current concerns within Spanish population. Women participating in this study had different hunger profiles and a wide range of body weight excess. Half of the women felt that their main difficulty was excessive 
Table 4: FS and FS+Diet Groups whole Results. Differences between Measurements at Week 8 and First Day of weight (W1-W3), Body Mass Index (BMI1-BMI3), Fat Mass Percentage (FM1-FM3), Waist Circumference (Wci1-Wci3) and Hip Circumference (Hci1-Hci3), within the whole Group and Women with a Good Performance (GP)

\begin{tabular}{|c|c|c|c|c|c|}
\hline FS & & & & & Wci1-Wci3 \\
\hline & W1-W3 & BMI1-BMI3 & FM1-FM3 & $-1,686$ & Hci1-Hci3 \\
\hline \hline Total $(n=128)$ & $-2,21$ & $-0,798$ & $-2,314$ & $-1,771$ \\
\hline GP $(n=38)$ & $-2,82$ & $-1,01$ & $-3,95$ & $-2,26$ \\
\hline FS+diet & & & & Wci1-Wci3 & Hci1-Hci3 \\
\hline \hline Total $(n=124)$ & W1-W3 & BMI1-BMI3 & FM1-FM3 & $-4,55$ & $-4,71$ \\
\hline GP $(n=56)$ & $-4,61$ & $-1,476$ & $-2,65$ & $-5,03$ & $-4,98$ \\
\hline
\end{tabular}

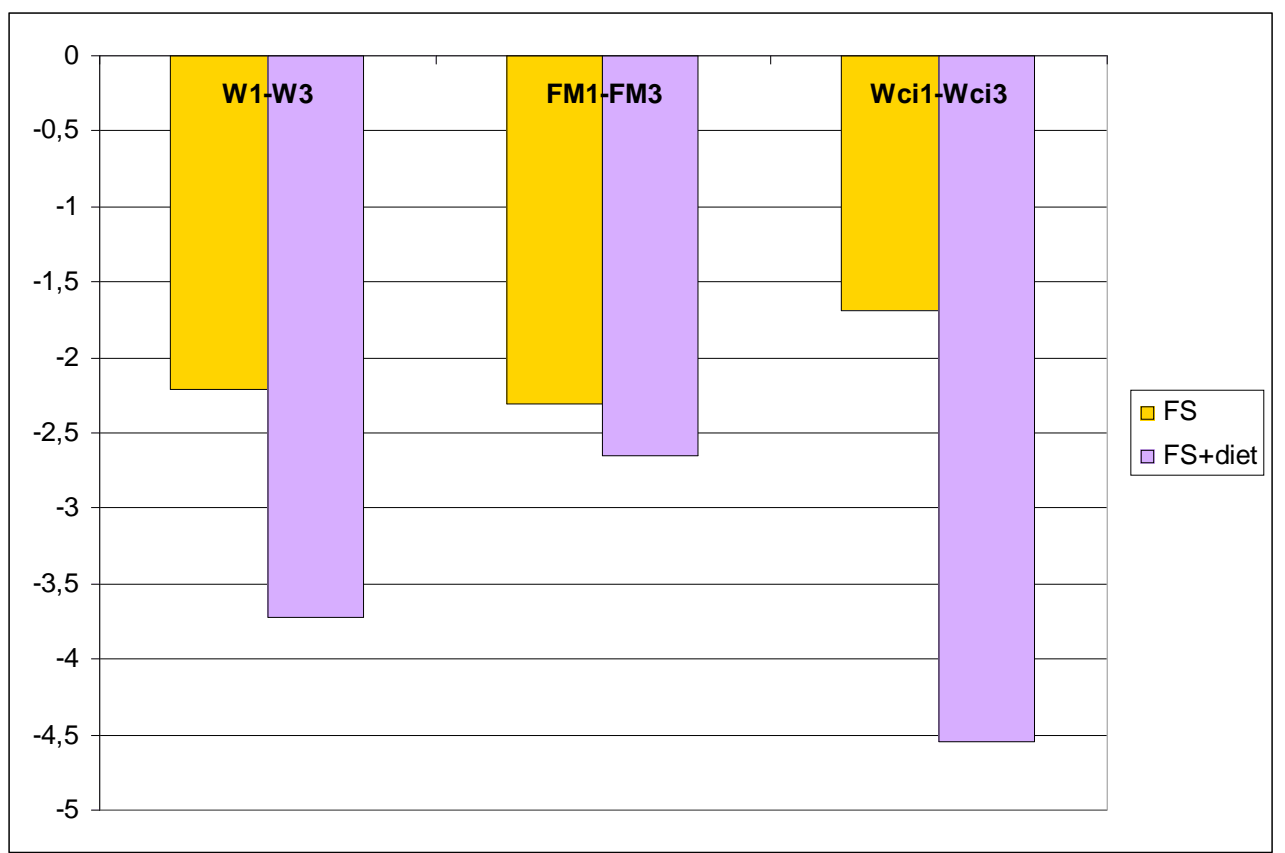

Figure 3: Compared results of weight (W), fat mass percentage (FM), and waist circumference (Wci) between FS and FS+diet groups.

appetite at mealtimes, and half felt anxiety leading to snacking behaviour during the day. Anthropometric parameters were higher than expected, highlighting frequent situations of grade II overweight and even obesity. Most of the women who participated in this program were within the overweight in the BMI range. FM corresponded mainly to overweight and also to obesity, even for those women who had normal BMI values. Waist circumference was in general higher than normal. FM and Wci were significantly higher in participants attending dietitian offices, probably due to greater weight problems leading them to seek professional help. Waist to hip ratio indicated that around one third of these participants had abdominal obesity and therefore cardiovascular risk.
During the 8 weeks program, both groups got significant results, achieving not only weight loss but also reduction in the body mass index, fat mass, and waist and hip circumferences. However, as expected, improvements were better in the FS+diet than in the FS group, probably due to the power of an individualised regime, but also due to the synergy of using food supplements along with a hypocaloric diet. This synergy may lead in two directions; food supplements were helpful in controlling hunger and therefore made it easier to follow-up the diet, and the fact of following a diet was also helpful to take food supplements as recommended. As a result, FS+diet women had better adherence to the program than the FS group, probably also due to greater initial motivation (they had already gone to the dietitian office when recruited). 
In summary, the varied characteristics of people who look for weight loss should be taken into account by health professionals reinforcing the need to tackle overweight and obesity in an individualised manner, with information about dietary background, hunger experience and anthropometric measures. The results of this modest study show that food supplements addressed to hunger management may be useful to weight management, especially when used along with a hypocaloric diet, and even more when used with personal assessment which seems to be a key motivational factor to achieve proper outcomes. More studies will be needed to assess the usefulness of specific food supplements promoting weight loss along with diet and exercise.

\section{ACKNOWLEDGEMENTS}

We are grateful to the financial support of Zambon S.A.U. which made possible the study and the program with Lipograsilß products. We also thank also llana Ventura for the final language review.

\section{CONFLICT OF INTERESTS}

LIA is associate professor at University of Barcelona but also holds a position at Zambon, S.A.U.

\section{REFERENCES}

[1] World Health Organization (WHO) [Global Health Observatory (GHO) Risk factors. Overweight] Geneva. WHO c2014. Available from: http://www.who.int/gho/ncd/risk_ factors/overweight_text/en/

[2] Ministerio de Sanidad, Servicios Sociales e Igualdad. ENSEEncuesta Nacional de Salud de España. Madrid 2012.

[3] Ministerio de Sanidad, Servicios Sociales e Igualdad. ENIDEEncuesta Nacional de la Ingesta Dietética de la población Española. Madrid 2011.

[4] Lean ME, Han TS, Morrison CE. Waist circumference as a measure for indicating the need for weight management. BMJ 1995; 311: 158-61.

http://dx.doi.org/10.1136/bmi.311.6998.158

[5] World Health Organization (WHO). Waist circumference and waist-hip ratio: report of a WHO expert consultation, Geneva 2008.

[6] Rubio MA, Salas-Salvadó J, Barbany M, Moreno B, Aranceta J, Bellido D, Blay V, Carraro R, Formiguera X, Foz M, de Pablos P, García-Luna PP, Griera JL, López de la Torre M, Alfredo Martínez J, Remesar X, Tebar J, Vidal J. Consenso SEEDO 2007 para la evaluación del sobrepeso y la obesidad y el establecimiento de criterios de intervención terapéutica. Rev Esp Obes 2007; 7-48.

[7] Zimmerman GL, Olsen CG, Bosworth MF 'Stages of change' approach to helping patients change behavior. Am Fam Physician 2000; 61: 1409-1416.

[8] Worsley A. Nutrition knowledge and food consumption: can nutrition knowledge change food behaviour? Asia Pac J Clin Nutr 2002; 11(Suppl): S579-S585.

http://dx.doi.org/10.1046/j.1440-6047.11.supp3.7.x
Chapman CD, Benedict C, Brooks SJ, Schiöth HB. Lifestyle determinants of the drive to eat: a meta-analysis. Am J Clin Nutr 2012; 96(3): 492-7. http://dx.doi.org/10.3945/ajcn.112.039750

[10] Maniam J, Morris MJ. The link between stress and feeding behaviour. Neuropharmacology 2012; 63(1): 97-110. http://dx.doi.org/10.1016/j.neuropharm.2012.04.017

[11] King NA, Horner K, Hills AP, Byrne NM, Wood RE, Bryant E, Caudwell P, Finlayson G, Gibbons C, Hopkins M, Martins C, Blundell JE. Exercise, appetite and weight management: understanding the compensatory responses in eating behaviour and how they contribute to variability in exerciseinduced weight loss. Br J Sports Med 2012; 46(5): 315-22.

[12] Benelam, B. Satiation, satiety and their effects on eating behaviour. Nutrition Bulletin 2009; 34: 126-173. http://dx.doi.org/10.1111/j.1467-3010.2009.01753.x

[13] Bellisle F, Drewnowski A, Anderson GH, WesterterpPlantenga M, Martin CK. Sweetness, satiation, and satiety. J Nutr 2012; 142(6): 1149S-54S.

[14] European Food Safety Authority (EFSA). Scientific Opinion Konjac mannan (glucomannan). EFSA J 2010; 8(10): 1798.

[15] Natural Medicines Comprehensive Database. Glucomannan Monograph. Therapeutic Research Center. Stockton 2012.

[16] González A, Fernández N, Sahagún AM, García JJ, Díez MJ, Calle AP, Castro LJ, Sierra M. Glucomanano: propiedades y aplicaciones terapéuticas. Nutr Hosp 2004; XIX(1): 45-50.

[17] Micromedex. Glucomannan Monograph. AltMedDex. USA 2012.

[18] Hess JR, Birkett AM, Thomas W, Slavin JL. Effects of shortchain fructooligosaccharides on satiety responses in healthy men and women. Appetite 2011; 56: 128-134. http://dx.doi.org/10.1016/j.appet.2010.12.005

[19] El Khoury D, Cuda C, Luhovyy BL, Anderson GH. Beta Glucan: Health Benefits in Obesity and Metabolic Syndrome. Review article. Journal of Nutrition and Metabolism 2012; 2012: 851362.

[20] European Food Safety Authority (EFSA). Scientific Opinion Beta-glucans from oat. EFSA Journal 2011; 9(6): 2207

[21] Natural Medicines Comprehensive Database. Beta-glucan Monograph. Therapeutic Research Center. Stockton 2013.

[22] European Food Safety Authority (EFSA). Scientific Opinion Chromium. EFSA Journal 2010; 8(10): 1732.

[23] Anderson RA. Effects of Chromium on Body Composition and Weight Loss. Nutrition Reviews 1998; 56 (9): 266-270. http://dx.doi.org/10.1111/j.1753-4887.1998.tb01763.x

[24] Onakpoya I, Posadzki P, Ernst E. Chromium supplementation in overweight and obesity: a systematic review and meta-analysis of randomized clinical trials. Obes Rev 2013; 14(6): 496-507. http://dx.doi.org/10.1111/obr.12026

[25] Natural Medicines Comprehensive Database. Chromium Monograph. Therapeutic Research Center. Stockton 2012.

[26] Micromedex. Chromium Monograph. AltMedDex. USA 2012.

[27] Gouta B, Bourges C, Paineau-Dubreuil S. Satiereal, a Crocus sativus $L$ extract, reduces snacking and increases satiety in a randomized placebo-controlled study of mildly overweight, healthy women. Nutrition Research 2010; 30: 305-313.

http://dx.doi.org/10.1016/j.nutres.2010.04.008

[28] Srivastava R, Ahmed H, Dixit RK, Dharamveer, Saraf SA. Crocus sativus L.: A comprehensive review. Pharmacogn Rev 2010; 4(8): 200-208. http://dx.doi.org/10.4103/0973-7847.70919

[29] Natural Medicines Comprehensive Database. Saffron Monograph. Stockton 2013. 
[30] Ulbricht C, Conquer J, Costa D, Hollands W, lannuzzi C, Isaac R, Jordan JK, Ledesma N, Ostroff C, Serrano JM, Shaffer MD, Varghese M. An evidence-based systematic review of saffron (Crocus sativus) by the Natural Standard Research Collaboration. J Diet Suppl 2011; 8(1): 58-114. http://dx.doi.org/10.3109/19390211.2011.547666
[31] Hausenblas HA, Saha D, Dubyak PJ, Anton SD. Saffron (Crocus sativus L.) and major depressive disorder: a metaanalysis of randomized clinical trials. J Integr Med 2013; 11(6): 377-83.

Received on 10-09-2014

Published on 11-11-2014

DOI: http://dx.doi.org/10.6000/1927-5951.2014.04.04.2

(C) 2014 Rafecas et al.; Licensee Lifescience Global.

This is an open access article licensed under the terms of the Creative Commons Attribution Non-Commercial License (http://creativecommons.org/licenses/by-nc/3.0/) which permits unrestricted, non-commercial use, distribution and reproduction in any medium, provided the work is properly cited. 